\title{
An overview of prostate diseases and their characteristics specific to Asian men
}

\author{
Shu-Jie Xia, Di Cui and Qi Jiang
}

In this paper, we reviewed the features of common prostate diseases, such as benign prostatic hyperplasia (BPH), prostate cancer (PCa) and chronic prostatitis (CP) that are specific to Asian men. Compared to the Westerners, Asians exhibit particular characteristics of prostate diseases. Through summarizing the epidemiology, symptomatology, diagnostics and therapeutics of these diseases, we find that Asians have a lower incidence of PCa than whites, but the incidences of BPH and CP are similar. Asian men with CP often suffer from fewer disease sites, but have a higher frequency of pain during urination rather than after sexual climax. Prostate-specific antigen (PSA) is a widely used marker for the diagnosis of PCa in both Asian and Western countries. Although the PSA level may be lower in Asians, the threshold used is based on whites. After reviewing the treatments available for these diseases, we did not find a fundamental difference between Asians and whites. Furthermore, the selection for the most appropriate treatment based on the individual needs of patients remains a challenge to urologists in Asia. After considering the traits of prostate diseases that are specific to Asian men, we hope to pave the way for the development of specific diagnostic and therapeutic strategies targeted specifically to Asian men. Asian Journal of Andrology (2012) 14, 458-464; doi:10.1038/aja.2010.137; published online 6 February 2012

Keywords: Asians; benign prostatic hyperplasia; chronic prostatitis; prostate cancer

\section{INTRODUCTION}

Prostate diseases are common diseases in urology. Benign prostatic hyperplasia $(\mathrm{BPH})$, prostate cancer $(\mathrm{PCa})$ and chronic prostatitis (CP) are the most frequent. Asians and whites exhibit differences in race, diet, lifestyle and environmental factors; thus, these three prostate diseases have features that are specific to Asian men. Therefore, we reviewed these features with respect to epidemiology, symptomatology, diagnostics and therapeutics. After considering the characteristics of prostate diseases that are specific to Asians, we hope to pave the way for the development of specific diagnostic and therapeutic strategies targeted specifically to Asian men.

\section{BENIGN PROSTATIC HYPERPLASIA (BPH)}

\section{Ethnic features}

$\mathrm{BPH}$ is a common disease among men attending urology clinics. Early clinical observations and studies have shown that Asians generally have a similar or higher International Prostate Symptom Score (IPSS) compared with whites (Table 1). ${ }^{1,2}$ However, the differences in the prostate tissue between Asians and whites may deserve special mention with regard to BPH. First, the cellular composition of the prostate may be different. The prostates of Chinese men contain significantly more glandular lumens and less smooth muscle and connective tissue than Caucasian-Americans. ${ }^{3}$ Second, Korean men have been shown to have a higher transition zone enlargement ratio relative to total prostate volume in comparison to Caucasians and Hispanics. ${ }^{2}$
Lower urinary tract symptoms (LUTS)

BPH patients in Asian countries typically have accompanying LUTS. ${ }^{4}$ Traditionally, LUTS are considered a consequence of BPH-related prostate enlargement. However, the theory that there is a simplistic causal relationship between them has been challenged. Recently, LUTS have been considered not only attributable to prostatic enlargement, but also to the aging of the bladder muscle, metabolic factors and prostatic inflammation, a dynamic component of the smooth muscle tone of the prostate, serum sex steroid hormones and other factors. ${ }^{5-8}$

LUTS can be categorized as storage symptoms, voiding symptoms and postmicturition symptoms. The most common symptom in both Asians and whites is nocturia. ${ }^{4,9,10}$ In addition to the symptoms mentioned above, patients with LUTS also suffer sexual dysfunctions, which are correlated with the severity of LUTS. ${ }^{11-13}$ In a survey of five regions of Southeast Asia, $82 \%$ of men with LUTS experienced sexual dysfunction. The most common sexual problems were erectile dysfunction (ED) (71\%), reduced ejaculation (66\%) and pain with ejaculation (18\%). ${ }^{4}$ The link between LUTS and ED has been attributed to the following factors: (i) the autonomic hyperactivity and metabolic syndrome hypothesis; (ii) a decrease in the release of nitric oxide in the penis and the prostate; (iii) the activation of Rho kinase and the endothelin pathway; (iv) pelvic arteriosclerosis; and (v) an altered composition of the myosin isoform. ${ }^{14,15}$

\section{$\mathrm{BPH}$ progression parameters}

In Asian men, BPH usually begins in the fourth decade of life and is attributed to dynamic changes with age in the glandular tissue 
Table 1 Age-specific prevalence of men with IPSS $\geqslant 8$ in various areas $^{1}$

\begin{tabular}{lcccc}
\hline \multirow{2}{*}{ Area } & \multicolumn{4}{c}{ Prevalence of men with IPSS $\geqslant 8(\%)$} \\
\cline { 2 - 5 } & $40-49$ years & $50-59$ years & $60-69$ years & $70-79$ years \\
\hline Asia $^{a}$ & $18 \%$ & $29 \%$ & $40 \%$ & $56 \%$ \\
Australia & - & $36 \%$ & $33 \%$ & $37 \%$ \\
USA & $12 \%$ & $17 \%$ & $23 \%$ & $29 \%$ \\
Canada & - & $15 \%$ & $27 \%$ & $31 \%$ \\
France & - & $8 \%$ & $14 \%$ & $27 \%$ \\
The Netherlands & - & $26 \%$ & $30 \%$ & $36 \%$ \\
\hline
\end{tabular}

Abbreviation: IPSS, International Prostate Symptom Scores.

${ }^{a}$ Asian data were obtained from mainland China, Taiwan (China), Korea, the Philippines, Thailand, Singapore, Pakistan and India.

composition and cell proliferation activity. ${ }^{16-18}$ There are several useful parameters to identify the risk of BPH progression, including age, prostate volume and serum prostate-specific antigen (PSA) level. ${ }^{19,20}$ Intravesical prostatic protrusion level is also a useful parameter. ${ }^{19}$ Interestingly, there are some links between these parameters, including an age-dependent trend towards increased prostate volume with a greater intravesical prostatic protrusion level. Meanwhile, serum PSA level is significantly correlated with prostate volume in Asian communities. $^{21-26}$

\section{Treatment: the current situation, trends and challenges}

Generally speaking, drugs and surgery are two main treatment options for BPH. Some trends have been discovered in the last few decades. The utilisation of pharmaceutical therapy is increasingly the first choice for BPH treatment. ${ }^{27}$ While the use of transurethral prostatectomy (TURP) has been challenged by minimally invasive surgical therapy (MIST), ${ }^{28,29}$ it remains the gold standard of ablative therapy.

$\alpha_{1}$-blockers and $5 \alpha$-reductase inhibitors are the two classes of medications that are recommended by the European Association of Urology guidelines for the medical management of LUTS/BPH. ${ }^{30}$ In Asian countries, clinical evidence has demonstrated that this medical therapy relieves the symptoms of patients. ${ }^{18,31}$ In addition, the combination of these two classes of drugs has been proven to significantly reduce the relative risk of clinical progression of $\mathrm{BPH}$, and the relief of LUTS is greater in combination than when either drug is used alone. However, the effect on reducing the relative risk of acute urinary retention or BPH-related surgery remains controversial. ${ }^{20,32-36}$ Furthermore, the combination of $\alpha_{1}$-blockers with antimuscarinic agents is useful for relieving symptoms of LUT/BPH without increasing urinary retention. ${ }^{33,37} \mathrm{~A}$ comparison of different $\alpha_{1}$-blockers in the same individuals demonstrated no statistically significant difference between terazosin ( $5 \mathrm{mg}$ daily) and alfuzosin (10 mg daily) for 3 months in the IPSS and maximum flow rate. ${ }^{38}$
As LUTS associated with BPH are generally accompanied by sexual dysfunction, many clinical trials have indicated that combination therapy is the optimal treatment. Randomized placebo-controlled trials have shown that PDE5 inhibitors, which are used for the treatment of patients with ED, improved voiding and storage in LUTS/ BPH. ${ }^{39-41}$ A clinical study showed that combining tadalafil and alfuzosin resulted in greater improvements in ED, IPSS and International Index of Erectile Function scores than either drug used alone. ${ }^{42}$ Similarly, an in vitro experiment using this combination showed an additive relaxant effect on human prostate and detrusor tissue. ${ }^{43}$ However, one survey reported that sildenafil and tamsulosin used in combination is not superior to monotherapy in treating LUTS and ED. ${ }^{44}$ In Asian men, alfuzosin improved ejaculatory function, while tamsulosin had a slight negative impact on ejaculation. ${ }^{45-48}$ Rosen et al. ${ }^{49}$ reported that alfuzosin, doxazosin and terazosin appeared to be associated with better ejaculatory function than tamsulosin.

Although the medical treatment of $\mathrm{BPH}$ is well established, the following questions remain:

1. How long and for whom should combination therapy of $\alpha_{1}$ blockers and $5 \alpha$-reductase inhibitors be utilized? ${ }^{36}$

2. Does tamsulosin elicit an apoptotic response to reduce the prostate volume ${ }^{50}$

3. Which PDE5 inhibitors are the most effective, safe and costeffective for treating LUTS/BPH?

4. What are the long-term outcomes of combination therapy with $\alpha_{1}$-blockers and PDE5 inhibitors in the treatment of LUTS/BPH. ${ }^{51}$

As the gold standard of surgical therapy, TURP is the most commonly used surgical option. ${ }^{29}$ However, new minimally invasive surgical techniques, such as the bipolar modification of TURP (bipolar TURP or bipolar transurethral resection of prostate), various laserassisted techniques (holmium laser eucleation/resection of the prostate, photo-selective vaporization of the prostate and thulium laser) and plasmakinetic enucleation has grown in popularity. ${ }^{52}$

Many clinical studies have indicated that these MISTs are safe and effective compared to TURP. Recently, two meta-analyses have compared MIST and TURP. ${ }^{53,54}$ The efficacy of each is shown in Table 2, and the analyses found that bipolar TURP and bipolar transurethral electrovaporization of the prostate are comparable to TURP in shortand medium-term follow-up, while photo-selective vaporization of the prostate may be effective only in small to midsized prostates. They also concluded that holmium laser eucleation of the prostate (HoLEP) is at least as effective as TURP in long-term follow-up. Among surgical complications, catheter time following TURP was found to be the longest among all the techniques, and all adverse interand peri-operative events were significantly less frequent following MIST compared to TURP. Considering the limited long-term follow-up data after MIST and the low complication rate of TURP, the durability of TURP outcomes is still not surpassed. ${ }^{53,54}$

Table 2 Comparisons of efficacy in different transurethral procedures and TURP ${ }^{53}$

\begin{tabular}{|c|c|c|c|c|c|c|c|c|}
\hline & \multicolumn{2}{|l|}{ IPSS } & \multicolumn{2}{|c|}{ Qmax } & \multicolumn{2}{|c|}{ PVR } & \multicolumn{2}{|c|}{ QoL } \\
\hline & Mean difference & $\mathrm{P}$ value & Mean difference & $\mathrm{P}$ value & Mean difference & $\mathrm{P}$ value & Mean difference & $\mathrm{P}$ value \\
\hline Bipolar TURP vs. TURP & 0.094 & 0.827 & -0.539 & 0.070 & 3.677 & 0.416 & -0.100 & 0.502 \\
\hline Bipolar TUVP vs. TURP & -0.060 & 0.900 & -1.696 & 0.052 & -12.866 & 0.584 & -0.286 & 0.386 \\
\hline HoLEP vs. TURP & 1.309 & 0.005 & 1.687 & 0.012 & 5.667 & 0.196 & -0.003 & 0.978 \\
\hline PVP vs. TURP & -5.377 & 0.146 & -1.826 & 0.414 & -42.644 & 0.158 & - & - \\
\hline
\end{tabular}

Abbreviations: HoLEP, holmium laser eucleation of the prostate; IPSS, international prostate symptom scores; PVP, photo-selective vaporization of the prostate; PVR, postvoid residual volume; Qmax, maximum flow rate; QoL, quality of life score in IPSS; TURP, transurethral resection of prostate; TUVP, transurethral electrovaporisation of prostate. 
Additionally, a systematic review reported that the outcome of male sexual function after holmium laser surgery and TURP were similar. Some patients reported decreased erectile function (HoLEP: $7.5 \%$ vs. TURP: 7.7\%), while some reported increased function (HoLEP: $7.1 \%$ vs. TURP: $6.2 \%$ ). There were high incidences of ejaculatory dysfunction following both holmium laser surgery and TURP. ${ }^{55}$

Currently, the choice of the most appropriate surgical treatment for individual patients with $\mathrm{BPH}$ remains challenging.

\section{PROSTATE CANCER (PCA)}

\section{Epidemiological characteristics}

It is well established that the incidence and mortality rates of PCa are significantly lower in Asia than in Western countries. Recently, important new epidemiological studies have been published showing several findings. ${ }^{56-58}$ First, the incidence of PCa has risen over the last two decades (Table 3). Second, the stage distributions of PCa are more unfavourable in Asians, with a higher occurrence of medium- or highgrade PCa than whites. Third, mortality rates of PCa may continue to rise in most Asian countries. For instance, in South Korea, PCa mortality increased 12.7 -fold over a 20 -year period. ${ }^{59}$ This may be attributable to genetic factors, such as a gradual westernisation of lifestyle, increased dietary fat intake, environmental changes or a low rate of PSA screening in Asia. ${ }^{58-61}$

\section{Diagnosis: PSA and other tumour markers}

Serum PSA is a tumour marker that is currently used for PCa screening and diagnosis in both Asian and Western countries. Currently, the generally accepted upper cut-off level of normal PSA is $4.0 \mathrm{ng} \mathrm{ml}^{-1}$ in Asians and whites. However, this cut-off level has limited specificity and sensitivity for the clinical diagnosis of PCa. Regarding specificity, the PSA level can be affected by several factors, such as age, body surface area, body mass index, prostate volume, prostatitis and medical or surgical interventions. ${ }^{21,24,61-64}$ In terms of sensitivity, PSA levels less than $4.0 \mathrm{ng} \mathrm{ml}^{-1}$ were found in $15.2 \%$ of PCa patients in the United States of America, 23\% of PCa patients in Europe and $12.4 \%$ of PCa patients in Asia. ${ }^{61,65-67}$

Because of the drawbacks of using the PSA level for the detection of PCa, many PSA derivatives have appeared. The most accurate PSA derivative is the ratio of free PSA to total PSA, and the recommend cutoff is $0.14-0.16$ in some Asian countries. ${ }^{68,69}$ At the same time, PSA density, PSA velocity and PSA doubling time are also used occasionally. ${ }^{70}$ A combination of these indices may reduce the number of repeat biopsies when the PSA level is between 4 and $10 \mathrm{ng} \mathrm{ml}^{-1}$. $^{71}$ Besides PSA and its derivatives, other new markers that have been used include early PCa antigen, ${ }^{72}$ and urinary PCa gene $3{ }^{70,73-75}$

PSA levels may be lower and prostate volumes may be smaller in Asians compared to whites, but Asians may have a higher PSA level per unit volume. This evidence is shown in studies among Korean,
Japanese, Chinese, Malay, Indian and Arab men..$^{21,26,76-81}$ However, Asians often use the PSA threshold that is based on whites. Therefore, additional and collaborative clinical studies should be conducted in order to establish separate PSA cut-off values or nomograms for Asian men. $^{58}$

\section{Diagnosis: prostate biopsy}

A prostate biopsy is strongly indicated for patients with a PSA level above $10 \mathrm{ng} \mathrm{ml}{ }^{-1} .{ }^{82}$ Sextant biopsy has been the gold standard for several years. However, some recent studies have demonstrated that 10-14 core-extended biopsy is optimal for first-time prostate biopsy. ${ }^{63,83-85}$ In order to predict a positive biopsy, some parameters and nomograms can be used, such as positive digital rectal examination results, prostate volume and hypo-echoic lesions on TRUS. ${ }^{65,86-93}$ For patients with clinically suspected PCa but a negative first biopsy, a saturation biopsy (minimum of 20 cores) with lateral and apical cores may be indicated, which is also efficacious for staging patients who are undergoing active surveillance protocols, ${ }^{63,85,94,95}$ Pepe et al..$^{96}$ suggested that in addition to the presence of LUTS, TURP should be a part of the diagnostic procedure in cases of a repeated negative saturation biopsy. Meanwhile, the sample from the prostatic transition zone by directed needle biopsies may be omitted due to a lower detection rate compared to TURP. ${ }^{97,98}$

\section{Initial therapy in primary localized PCa}

Initial therapy in primary localized PCa includes radical prostatectomy (RP), hormone therapy (HT), brachytherapy and external-beam radiation therapy $(\mathrm{RT})$.

$\mathrm{RP}$ can be performed either by retropubic radical prostatectomy (RRP) or laparoscopic radical prostatectomy (LRP). A study among Asians showed that LRP is comparable to RRP with no significant morbidity and a positive surgical margin rate. Meanwhile, LRP has been reported to have decreased blood loss and decreased need for blood transfusion, but also extends operative time. ${ }^{99}$

Furthermore, robot-assisted LRP is a new option that has been widely used in America and many parts of Europe, though it is in its infancy in Asia. Until 2009, only eight regions had a robot system; in total there were 24 systems in Asian countries, namely in the mainland of China, South Korea, Japan, Taiwan (China), India, Thailand, Singapore and Malaysia. It is uncertain whether robotic surgery will result in superior oncologic and functional outcomes and decreased postoperative morbidity in Asians. ${ }^{100}$ Yip et al. ${ }^{101}$ painted a rosy outlook of robotic prostatectomy in Asia after viewing the evolving trends in East Asia.

HT is known to be beneficial in high-risk and advanced PCa. Although its benefits in low- or intermediate-risk PCa remains controversial, ${ }^{102}$ it is widely used as the initial treatment in Asian countries such as Korea, Japan, China, Singapore, Indonesia and Vietnam. ${ }^{58,103}$

Table 3 Incidence and mortality rates of prostate cancer in seven Asian countries (per 100000 person-year, age-adjusted using the world standard) ${ }^{56,59,143-145}$

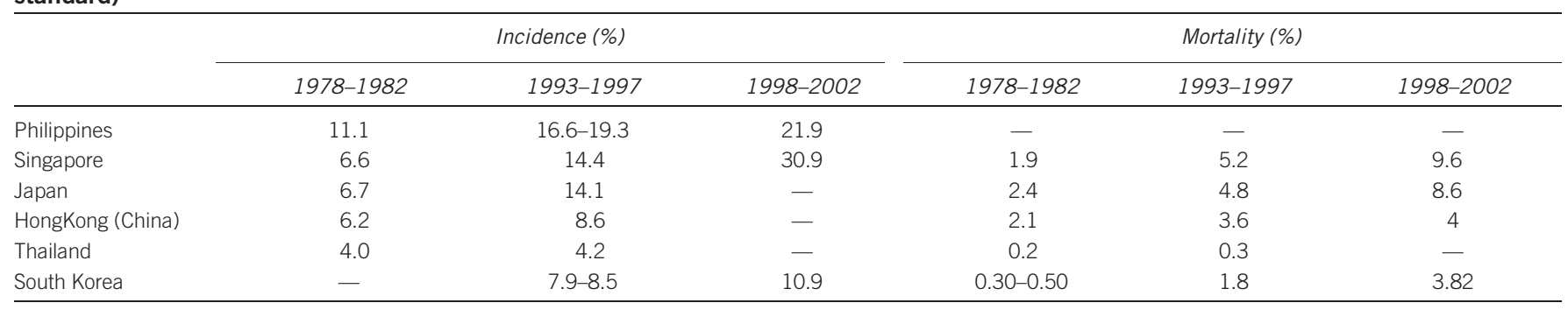


A marked racial difference in the clinical outcome after HT has been observed between Asians and Caucasians. ${ }^{104,105}$ Japanese men had a better overall and cause-specific survival rate compared with Caucasian men $(P=0.001$ and 0.036$)$. Chinese men demonstrated a similar trend. ${ }^{58}$

Unlike HT, brachytherapy and external-beam RT are not routinely used in most Asian areas. ${ }^{103,106,107}$ Therefore, few data can be found regarding the outcome of these two therapies in Asian men.

In intermediate-risk PCa, Vassil et al. ${ }^{102}$ recently demonstrated that choosing RRP, brachytherapy or RT appeared to improve 5-year biochemical relapse-free survival and delayed salvage therapy compared with LRP.

In high-risk PCa, RP is commonly used as the primary therapy. However, more than $50 \%$ of PCa patients in Asia are treated using HT. Furthermore, a combined androgen blockade (CAB), which consists of luteinizing hormone-releasing hormone agonists plus an anti-androgen, was more effective than hormone monotherapy in terms of disease-specific survival in high-risk PCa in Asia (Table 4) $(P=0.037) .{ }^{108}$ A survey in Japan showed that $\mathrm{RT}+\mathrm{HT}$ resulted in significantly better survival rates compared with primary HT $(P=0.029)$. There were, however, no statistically significant differences between $\mathrm{RT}+\mathrm{HT}$ and $\mathrm{RP}+\mathrm{HT}$ or between $\mathrm{RP}+\mathrm{HT}$ and primary HT. ${ }^{109}$ Mizokami et al. ${ }^{108}$ suggested that in high-risk patients with an initial PSA level of $\leqslant 20 \mathrm{ng} \mathrm{ml}^{-1}$, a Gleason score of $\leqslant 6$ and a nadir in the PSA of $\leqslant 0.2 \mathrm{ng} \mathrm{ml}^{-1}$ within 6 months of HT, monotherapy using $\mathrm{RP}, \mathrm{RT}$ or HT is likely to be effective. Combined therapies with CAB and brachytherapy may be useful for higher grade and stage tumours. One study in Taiwan (China) showed that high-dose brachytherapy plus RT can achieve satisfactory biochemical control with acceptable complications for T1c to T3a PCa patients. ${ }^{110}$

In local advanced $\mathrm{PCa}$, androgen deprivation therapy is the main treatment strategy. However, to prolong the period before PCa becomes refractory to HT, complementary treatments following androgen deprivation therapy should be considered with RT being a common choice. ${ }^{111}$ Recently, Wu et al. ${ }^{112}$ reported that in Chinese patients who had undergone androgen deprivation therapy, highintensity focused ultrasound combined with low-dose RT resulted in a higher 5-year disease-specific survival rate than both conventional-dose RT and high-intensity focused ultrasound $(75.29 \%$ vs. $64.47 \%$ and $46.35 \%$, respectively) with lower incidences of radiation-related late gastrointestinal and genitourinary toxicity grades. Additionally, RP may be considered in selected cases of local advanced PCa, with 5-year PSA-free survival rates at from $45 \%$ to $62 \%$. The European Association of Urology guidelines recommend that only

Table 4 Five- and ten-year survival rates after different treatments for high-risk prostate cancer

5-year survival rate 10-year survival rate $\mathrm{P}$ value

(\%) (\%)

\begin{tabular}{lccc}
\hline Mizokami et al. ${ }^{108}$ & & & \\
CAB & 92.8 & 92.8 & \\
Hormone monotherapy & 87.4 & 78.5 & 0.037 \\
Saito et al. ${ }^{109}$ & & & \\
RT+HT & 96.6 & 93.6 & \\
RP+HT & 93.8 & 71.4 & $0.029^{a}$ \\
Primary HT & 88.6 & 62.3 & \\
\hline
\end{tabular}

Abbreviations: $\mathrm{CAB}$, combined androgen blockade; HT, hormone therapy; RP, radical prostatectomy; $\mathrm{RT}$, radiationtherapy.

${ }^{\mathrm{a}} \mathrm{RT}+\mathrm{HT}$ vs. primary HT.
cT3a patients with a PSA level of $<20 \mathrm{ng} \mathrm{ml}^{-1}$ and a biopsy Gleason score of $\leqslant 8$ are suitable for this strategy. ${ }^{113}$

\section{PROSTATITIS}

Currently, CP syndromes represent an important healthcare problem worldwide. In many Asian countries, the direct and indirect costs (e.g., work and productivity loss) associated with CP are large and pose significant financial burdens for men. ${ }^{114,115}$ In Iran, CP is one of the six greatest burdens of urologic diseases. ${ }^{116}$ In China, the treatment of one CP patient usually costs $\$ 1151$ per year. ${ }^{117}$

\section{Symptomatology features}

According to the recommended National Institutes of Health categorisation system, ${ }^{118}$ chronic prostatitis/chronic pelvic pain syndrome (CP/CPPS) is the most common form of prostatitis. The prevalence of prostatitis-like symptoms in China is $8.4 \%$ and the prevalence of CP was $4.5 \%$ in an investigation of 12743 Chinese men. ${ }^{119}$ In a metaanalysis of five studies (three from America and two from Asia), Krieger et al. ${ }^{120}$ reported that the prevalence of prostatitis symptoms ranged from $2.2 \%$ to $9.7 \%$, with a median rate of $8.7 \%$. There are also reports showing that $4.9 \%-10.5 \%$ of men from North American, Europe and Asia have prostatitis-like symptoms. ${ }^{121-124}$ To date, there is no direct evidence to demonstrate that regional or ethnic factors are related to the prevalence of $\mathrm{CP}$. However, differences in the basic clinical characteristics of CP/CPPS between North Americans and Asians are truly interesting. Lee et al. ${ }^{125}$ showed a lower quality of life, a shorter duration of CP/CPPS symptoms, and fewer disease sites, as well as a higher frequency of pain in Asian men than American men. In these men, the pain generally occurred during urination rather than after sexual climax. However, the National Institutes of Health Chronic Prostatitis Symptom Index total scores, the pain plus urinary subscores, and the average pain level were similar between Asian and North American men. ${ }^{125}$

Besides discomfort or pain in the lower genitourinary tract or perineum, sexual dysfunction is also a threat to men with CP/CPPS. CP symptoms were significantly correlated with the indices of sexual function in the patients and their quality of sexual life. Premature ejaculation and ED are common complications of CP. ${ }^{18,126-131}$

\section{Treatment: confusion and multimodal therapy}

From the data presented above, we consider CP/CPPS to be a significant problem for men with a spectrum of urological diseases. However, urologists generally experience much confusion and frustration in the management of CP because the treatment efficacy is unsatisfactory. ${ }^{117,132,133}$ In clinical practice, pharmacotherapy (antibiotics and $\alpha$-blockers) is the most commonly used treatment and is primarily used to relieve patients' discomfort, even though urologists know that CP/CPPS is not a bacterial disease. ${ }^{117,132}$ However, some studies have confirmed that medical therapy is truly effective to some patients. ${ }^{134}$ Antibiotics have been reported to be useful in the treatment of premature ejaculation in CP/CPPS. ${ }^{135,136}$ For those who failed this therapy, several additional methods have been tried, including anti-inflammatory drugs, pollen extract, sitz baths, prostate massage and pelvic floor physical therapy. ${ }^{17,132-134,137-139}$ Some evidence suggests that CP/CPPS may be neuropathic in origin, and treatment based on that theory might provide greater treatment options. One retrospective analysis in China showed that chlormezanone (a drug for anxiety) may relieve CP/CPPS symptoms. ${ }^{140}$ However, no single attempt has shown efficiency for the cure of CP/CPPS. The current question is why so many therapies have failed to cure or control CP/ 
CPPS. Although the answer remains unknown, there are some studies and assumptions that can help answer the question. After finding a higher incidence of CPPS in females than in males, Marszalek et al. ${ }^{141}$ asked questions about the role of the prostate as the leading cause of $\mathrm{CP} / \mathrm{CPPS}$, and Zaak ${ }^{142}$ commented that a defect in urothelial permeability might play a role in CP/CPPS.

In general, multimodal therapy that includes pharmacotherapy, sitz baths, prostate massage and pelvic floor physical therapy may help patients to control the symptoms of CP/CPPS. Additional efforts should be made to more deeply understand the mechanism of $\mathrm{CP} /$ CPPS in order to find more effective therapy.

\section{CONCLUSION}

There is a high incidence of BPH in Asia. Age, prostate volume and PSA level may be useful parameters to identify the risk of BPH progression. LUTS are the most common symptom in BPH. However, LUTS are attributable not only to prostatic enlargement, but also to the aging of the bladder muscle, metabolic factors and prostatic inflammation, the dynamic component of the smooth muscle tone of the prostate, serum sex steroid hormones and other factors. The two main options to treat $\mathrm{BPH}$ are medical therapy and surgical treatment. A combination of $\alpha_{1}$-blockers and $5 \alpha$-reductase inhibitors are recommended. While new surgical therapies are continuously emerging and being developed, TURP rightly remains the dominant mode of treatment. Identifying the most appropriate treatment option and longterm management plan of each individual patient remains a great challenge.

The incidence of PCa is rapidly increasing in Asia. Although PSA level is the most widely used marker for PCa, the cut-off level suitable for Asians should be ascertained through large multicentre clinical trials, as should the protocol for prostate biopsy. RP, HT, brachytherapy and external RT are options for the treatment of localized PCa. In intermediate-risk PCa, RRP, brachytherapy and RT have similar 5year biochemical relapse-free survival rates. In high-risk and localized advanced PCa, combination therapy may show a higher survival rate.

CP/CPPS places a heavy burden on the health of Asian men. Conventional pharmaceutical therapy may fail in some patients. Multimodal therapy that combines pharmaceutical therapy, sitz baths, prostate massage and pelvic floor physical therapy may help patients better control the symptoms of CP/CPPS.

After reviewing BPH, PCa and CP/CPPS in Asian men, we conclude that Asians have distinct characteristics compared to the westerners regarding epidemiology, symptomatology and diagnostic methodology of prostate diseases, and urologists in Asian counties face bewildering complexities in their treatment. Additional efforts should be made to study these differences and treatment complexities in order to better manage prostate diseases and promote prostate health in Asian men.

1 Homma Y, Kawabe K, Tsukamoto T, Yamanaka H, Okada K et al. Epidemiologic survey of lower urinary tract symptoms in Asia and Australia using the international prostate symptom score. Int J Urol 1997; 4: 40-6.

2 Choi J, Ikeguchi EF, Lee SW, Choi HY, Te AE et al. Is the higher prevalence of benign prostatic hyperplasia related to lower urinary tract symptoms in Korean men due to a high transition zone index? Eur Urol 2002; 42: 7-11.

3 Lepor H, Shapiro E, Wang B, Liang YC. Comparison of the cellular composition of benign prostatic hyperplasia in Chinese and Caucasian-American men. Urology 1996; 47: 38-42.

4 Li MK, Garcia L, Patron N, Moh LC, Sundram M et al. An Asian multinational prospective observational registry of patients with benign prostatic hyperplasia, with a focus on comorbidities, lower urinary tract symptoms and sexual function. BJU Int 2008; 101: 197-202.
5 Bushman W. Etiology, epidemiology, and natural history of benign prostatic hyperplasia Urol Clin North Am 2009; 36: 403-15.

6 Byun SS, Jeong H, Jo MK, Lee E. Relative proportions of tissue components in the prostate: are they related to the development of symptomatic BPH in Korean men? Urology 2005; 66: 593-6.

7 Rohrmann S, Nelson WG, Rifai N, Kanarek N, Basaria S et al. Serum sex steroid hormones and lower urinary tract symptoms in Third National Health and Nutrition Examination Survey (NHANES III). Urology 2007; 69: 708-13.

8 Trifiro MD, Parsons JK, Palazzi-Churas K, Bergstrom J, Lakin C et al. Serum sex hormones and the 20-year risk of lower urinary tract symptoms in communitydwelling older men. BJU Int 2010; 105: 1554-9.

9 Sexton CC, Coyne KS, Kopp ZS, Irwin DE, Milsom I et al. The overlap of storage, voiding and postmicturition symptoms and implications for treatment seeking in the USA, UK and Sweden: EpiLUTS. BJU Int 2009; 103 Suppl 3: 12-23.

10 Irwin DE, Milsom I, Hunskaar S, Reilly K, Kopp Z et al. Population-based survey of urinary incontinence, overactive bladder, and other lower urinary tract symptoms in five countries: results of the EPIC study. Eur Urol 2006; 50: 1306-14; discussion $14-5$.

11 Li MK, Garcia LA, Rosen R. Lower urinary tract symptoms and male sexual dysfunction in Asia: a survey of ageing men from five Asian countries. BJU Int 2005; 96: 133954

12 Wong SY, Leung JC, Woo J. A prospective study on the association between lower urinary tract symptoms (LUTS) and erectile dysfunction: results from a large study in elderly Chinese in Southern China. J Sex Med 2009; 6: 2024-31.

13 Terai A, Ichioka K, Matsui Y, Yoshimura K. Association of lower urinary tract symptoms with erectile dysfunction in Japanese men. Urology 2004; 64: 132-6.

14 Yang J, Liu JH. Association between lower urinary tract symptoms and erectile dysfunction. Zhonghua Nan Ke Xue 2006; 12: 1026-9, 34. Chinese.

15 Lavalle LL, Almagro AA, Bravo CB, Martinez LC. Lower urinary tract symptoms and erectile dysfunction. Arch Esp Urol 2010; 63: 655-62.

16 Xia SJ, Xu XX, Teng JB, Xu CX, Tang XD. Characteristic pattern of human prostatic growth with age. Asian J Androl 2002; 4: 269-71.

17 Fujikawa S, Matsuura H, Kanai M, Fumino M, Ishii K et al. Natural history of human prostate gland: morphometric and histopathological analysis of Japanese men. Prostate 2005; 65: 355-64.

18 Chang HS, Park CH, Kim DK, Park JK, Hong SJ et al. Assessment of patient-reported outcome of patients with lower urinary tract symptoms suggestive of benign prostatic hyperplasia and treated with tamsulosin $\mathrm{HCl}$ in Korea. Urology 2010; 75: 1156-61.

19 Lieber MM, Jacobson DJ, McGree ME, St Sauver JL, Girman CJ et al. Intravesical prostatic protrusion in men in Olmsted County, Minnesota. J Urol 2009; 182: 2819 24

20 Pinto F, Racioppi M, Sacco E, Totaro A, Brescia A et al. Progression, risk factors and subsequent medical management of symptomatic benign prostatic hyperplasia. Arch Ital Urol Androl 2009; 81: 1-8.

21 Lee SE, Chung JS, Han BK, Moon KH, Hwang SI et al. Relationship of prostatespecific antigen and prostate volume in Korean men with biopsy-proven benign prostatic hyperplasia. Urology 2008; 71: 395-8.

22 Mao Q, Zheng X, Jia X, Wang Y, Qin J et al. Relationships between total/free prostatespecific antigen and prostate volume in Chinese men with biopsy-proven benign prostatic hyperplasia. Int Urol Nephrol 2009; 41: 761-6.

23 Gupta A, Aragaki C, Gotoh M, Masumori N, Ohshima S et al. Relationship between prostate specific antigen and indexes of prostate volume in Japanese men. J Urol 2005; 173: 503-6.

24 Kehinde EO, Mojiminiyi OA, Sheikh M, Al-Awadi KA, Daar AS et al. Age-specific reference levels of serum prostate-specific antigen and prostate volume in healthy Arab men. BJU Int 2005; 96: 308-12.

25 Tsukamoto T, Masumori N, Nakagawa H, Arai Y, Komiya A et al. Changes in prostate volume in Japanese patients with benign prostatic hyperplasia: association with other urological measures and risk of surgical intervention. Int J Urol 2009; 16: 622-7.

26 Khezri AA, Shirazi M, Ayatollahi SM, Lotfi M, Askarian M et al. Age specific reference levels of serum prostate-specific antigen, prostate volume and prostate specific antigen density in healthy Iranian men. Iran J Immunol 2009; 6: 40-8.

27 Howard DL, Taylor YJ, Ross LE. Differences in lower urinary tract symptoms, treatment and mortality among African-American and white elderly men. J Natl Med Assoc 2008; 100: 1146-52

28 Harkaway RC, Issa MM. Medical and minimally invasive therapies for the treatment of benign prostatic hyperplasia. Prostate Cancer Prostatic Dis 2006; 9: 204-14.

29 Smith RD, Patel A. Transurethral resection of the prostate revisited and updated. Curr Opin Urol 2011; 21: 36-41.

30 Cornu JN, Cussenot O, Haab F, Lukacs B. A widespread population study of actual medical management of lower urinary tract symptoms related to benign prostatic hyperplasia across Europe and beyond official clinical guidelines. Eur Urol 2010; 58: 450-6.

31 Xue Z, Zhang Y, Ding Q, He Z, Wang J et al. Doxazosin gastrointestinal therapeutic system versus tamsulosin for the treatment of benign prostatic hyperplasia: a study in Chinese patients. Int J Urol 2007; 14: 118-22.

32 Roehrborn CG, Siami P, Barkin J, Damiao R, Major-Walker $\mathrm{K}$ et al. The effects of combination therapy with dutasteride and tamsulosin on clinical outcomes in men with symptomatic benign prostatic hyperplasia: 4-year results from the CombAT study. Eur Urol 2010; 57: 123-31.

33 Greco KA, McVary KT. The role of combination medical therapy in benign prostatic hyperplasia. Int J Impot Res 2008; 20 Suppl 3: S33-43. 
34 Roehrborn CG, Siami P, Barkin J, Damiao R, Becher E et al. The influence of baseline parameters on changes in international prostate symptom score with dutasteride, tamsulosin, and combination therapy among men with symptomatic benign prostatic hyperplasia and an enlarged prostate: 2-year data from the CombAT study. Eur Urol 2009; 55: 461-71.

35 Miller J, Tarter TH. Combination therapy with dutasteride and tamsulosin for the treatment of symptomatic enlarged prostate. Clin Interv Aging 2009; 4: 251-8.

36 Barkin J. Management of benign prostatic hyperplasia by the primary care physician in the 21st century: the new paradigm. Can J Urol 2008; 15 Suppl 1:21-30; discussion 30.

37 Xiao H, Li HZ, Yang Y, Huang ZM, Li YQ et al. Clinical effectiveness and safety study of combined therapy with an alpha-blocker and an anticholinergic for patients with LUT/ BPH. Zhonghua Yi Xue Za Zhi 2007; 87: 1590-3. Chinese.

38 Senkul T, Yilmaz O, Iseri C, Adayener C, Akyol I et al. Comparing the therapeutic outcome of different alpha-blocker treatments for BPH in the same individuals. Int Urol Nephrol 2008; 40: 663-6.

39 Mulhall JP, Guhring P, Parker M, Hopps C. Assessment of the impact of sildenafil citrate on lower urinary tract symptoms in men with erectile dysfunction. J Sex Med 2006; 3: 662-7

40 Tamimi NA, Mincik I, Haughie S, Lamb J, Crossland A et al. A placebo-controlled study investigating the efficacy and safety of the phosphodiesterase type 5 inhibitor UK 369,003 for the treatment of men with lower urinary tract symptoms associated with clinical benign prostatic hyperplasia. BJU Int 2010; 106: 674-80.

41 Stief CG, Porst H, Neuser D, Beneke M, Ulbrich E. A randomised, placebo-controlled study to assess the efficacy of twice-daily vardenafil in the treatment of lower urinary tract symptoms secondary to benign prostatic hyperplasia. Eur Urol 2008; 53: 1236 44.

42 Oger S, Behr-Roussel D, Gorny D, Lecoz O, Lebret T et al. Combination of doxazosin and sildenafil exerts an additive relaxing effect compared with each compound alone on human cavernosal and prostatic tissue. J Sex Med 2009; 6: 836-47.

43 Oger S, Behr-Roussel D, Gorny D, Lebret T, Denoux Y et al. Combination of alfuzosin and tadalafil exerts an additive relaxant effect on human detrusor and prostatic tissues in vitro. Eur Urol 2010; 57: 699-707.

44 Tuncel A, Nalcacioglu V, Ener K, Aslan Y, Aydin 0 et al. Sildenafil citrate and tamsulosin combination is not superior to monotherapy in treating lower urinary tract symptoms and erectile dysfunction. World J Urol 2010; 28: 17-22.

45 Kim MK, Cheon J, Lee KS, Chung MK, Lee JY et al. An open, non-comparative multicentre study on the impact of alfuzosin on sexual function using the Male Sexual Health Questionnaire in patients with benign prostate hyperplasia. Int J Clin Pract 2010; 64: 345-50.

46 Kongkanand A, Chodchoy V, Lojanapiwat B, Pumpaisanchai S, Ratana-Olarn K et al. Safety and efficacy of a prolonged-release formulation of alfuzosin $10 \mathrm{mg}$ once daily in patients with lower urinary tract symptoms suggestive of benign prostatic hyperplasia. J Med Assoc Thai 2009; 92: 969-78.

47 Leungwattanakij S, Watanachote D, Noppakulsatit P, Petchpaibuol T, Choeypunt N et al. Sexuality and management of benign prostatic hyperplasia with alfuzosin SAMBA Thailand. J Sex Med 2010; 7: 3115-26.

48 Zlotta AR, Teillac P, Raynaud JP, Schulman CC. Evaluation of male sexual function in patients with lower urinary tract symptoms (LUTS) associated with benign prostatic hyperplasia (BPH) treated with a phytotherapeutic agent (Permixon), tamsulosin or finasteride. Eur Urol 2005; 48: 269-76.

49 Rosen RC, Wei JT, Althof SE, Seftel AD, Miner M et al. Association of sexual dysfunction with lower urinary tract symptoms of $\mathrm{BPH}$ and $\mathrm{BPH}$ medical therapies: results from the BPH Registry. Urology 2009; 73: 562-6.

50 Paick JS, Cho MC, Song SH, Kim SW, Ku JH. Impacts of the quinazoline-based alpha1-antagonist, terazosin, and of the sulfonamide derivative, tamsulosin, on serum prostate-specific antigen and prostate volume. J Korean Med Sci 2008; 23 509-13.

51 Wang C. Phosphodiesterase- 5 inhibitors and benign prostatic hyperplasia. Curr Opin Urol 2010; 20: 49-54.

52 Reich O, Seitz M, Gratzke C, Schlenker B, Walther S et al. Benign prostatic hyperplasia (BPH): surgical therapy options. Urologe A 2010; 49: 113-26. German.

53 Ahyai SA, Gilling P, Kaplan SA, Kuntz RM, Madersbacher S et al. Meta-analysis of functional outcomes and complications following transurethral procedures for lowe urinary tract symptoms resulting from benign prostatic enlargement. Eur Urol 2010 58: 384-97.

54 Burke N, Whelan JP, Goeree L, Hopkins RB, Campbell K et al. Systematic review and meta-analysis of transurethral resection of the prostate versus minimally invasive procedures for the treatment of benign prostatic obstruction. Urology 2010; 75: $1015-22$.

55 Frieben RW, Lin HC, Hinh PP, Berardinelli F, Canfield SE et al. The impact of minimally invasive surgeries for the treatment of symptomatic benign prostatic hyperplasia on male sexual function: a systematic review. Asian J Androl 2010; 12 500-8.

$56 \mathrm{Sim}$ HG, Cheng CWS. Changing demography of prostate cancer in Asia. Eur J Cancer 2005; 41: 834-45.

57 Pu YS, Chiang HS, Lin CC, Huang $\mathrm{CY}$, Huang KH et al. Changing trends of prostate cancer in Asia. Aging Male 2004; 7: 120-32.

58 Namiki M, Akaza H, Lee SE, Song JM, Umbas R et al. Prostate Cancer Working Group report. Jpn J Clin Oncol 2010; 40 Suppl 1: i70-5.

59 Park SK, Sakoda LC, Kang D, Chokkalingam AP, Lee E et al. Rising prostate cancer rates in South Korea. Prostate 2006; 66: 1285-91.
60 Singh J, Xie C, Yao M, Hua S, Vignarajan S et al. Food extracts consumed in Mediterranean countries and East Asia reduce protein concentrations of androgen receptor, phospho-protein kinase $\mathrm{B}$, and phospho-cytosolic phospholipase $\mathrm{A}_{2}$ alpha in human prostate cancer cells. J Nutr 2010; 140: 786-91.

61 Mousavi SM. Toward prostate cancer early detection in Iran. Asian Pac J Cancer Prev 2009; 10: 413-8.

62 Pinsky PF, Kramer BS, Crawford ED, Grubb RL, Urban DA et al. Prostate volume and prostate-specific antigen levels in men enrolled in a large screening trial. Urology 2006: 68: 352-6.

63 Chiang IN, Chang SJ, Pu YS, Huang KH, Yu HJ et al. Comparison of 6- and 12-core prostate biopsy in Taiwanese men: impact of total prostate-specific antigen, prostatespecific antigen density and prostate volume on prostate cancer detection. Urol Int 2009; 82: 270-5.

64 Bohnen AM, Groeneveld FP, Bosch JL. Serum prostate-specific antigen as a predictor of prostate volume in the community: the Krimpen study. Eur Urol 2007; 51:1645 52; discussion 52-3.

65 Ahyai SA, Graefen M, Steuber T, Haese A, Schlomm T et al. Contemporary prostate cancer prevalence among T1c biopsy-referred men with a prostate-specific antigen level <or=4.0 ng per milliliter. Eur Urol 2008; 53: 750-7.

66 Yang WJ, Lee DH, Chung BH, Cho JS, Choi YD et al. Detection rate of prostate cancer on biopsy according to serum prostate-specific antigen in Korean men: a multicenter study. Urology 2006; 67: 333-6.

67 Kobayashi T, Mitsumori K, Kawahara T, Nishizawa K, Ogura K et al. Prostate cancer detection among men with prostate specific antigen levels of 2.5 to $4.0 \mathrm{ng} / \mathrm{ml}$ in a Japanese urological referral population. J Urol 2006; 175: 1281-5.

68 Amirrasouli H, Kazerouni F, Sanadizade M, Sanadizade J, Kamalian N et al. Accurate cut-off point for free to total prostate-specific antigen ratio used to improve differentiation of prostate cancer from benign prostate hyperplasia in Iranian population. Urol J 2010; 7: 99-104.

69 Wang Y, Sun G, Pan JG, Guo ZJ, Li T. Performance of tPSA and f/tPSA for prostate cancer in Chinese. A systematic review and meta-analysis. Prostate Cancer Prostatic Dis 2006; 9: 374-8.

70 You J, Cozzi P, Walsh B, Willcox M, Kearsley J et al. Innovative biomarkers for prostate cancer early diagnosis and progression. Crit Rev Oncol Hematol 2010; 73: 10-22.

71 Okada K, Okihara K, Kitamura K, Mikami K, Ukimura $\mathrm{O}$ et al. Community-based prostate cancer screening in Japan: predicting factors for positive repeat biopsy. Int J Urol 2010; 17: 541-7.

72 Zhao Z, Zeng G, Zhong W. Serum early prostate cancer antigen (EPCA) as a significant predictor of incidental prostate cancer in patients undergoing transurethral resection of the prostate for benign prostatic hyperplasia. Prostate 2010; 70: 1788-98.

73 Haese A, de la Taille A, van Poppel H, Marberger M, Stenzl A et al. Clinical utility of the PCA3 urine assay in European men scheduled for repeat biopsy. Eur Urol 2008; 54. 1081-8.

74 van Gils MP, Hessels D, Peelen WP, Vergunst H, Mulders PF et al. Preliminary evaluation of the effect of dutasteride on PCA3 in post-DRE urine sediments: randomized, open-label, parallel-group pilot study. Prostate 2009; 69: 1624-34.

75 Talesa VN, Antognelli C, del Buono C, Stracci F, Serva MR et al. Diagnostic potential in prostate cancer of a panel of urinary molecular tumor markers. Cancer Biomark2009; 5: $241-51$.

76 Chung BH, Hong SJ, Cho JS, Seong DH. Relationship between serum prostate-specific antigen and prostate volume in Korean men with benign prostatic hyperplasia: a multicentre study. BJU Int 2006; 97: 742-6.

77 Shim HB, Lee JK, Jung TY, Ku JH. Serum prostate-specific antigen as a predictor of prostate volume in Korean men with lower urinary tract symptoms. Prostate Cancer Prostatic Dis 2007; 10: 143-8.

78 Masumori N, Tsukamoto T, Kumamoto Y, Miyake H, Rhodes T et al. Japanese men have smaller prostate volumes but comparable urinary flow rates relative to American men: results of community based studies in 2 countries. J Urol 1996: 155: 1324-7.

79 Chang YL, Lin AT, Chen KK, Chang YH, Wu HH et al. Correlation between serum prostate specific antigen and prostate volume in Taiwanese men with biopsy proven benign prostatic hyperplasia. J Urol 2006; 176: 196-9.

80 Chia SE, Lau WK, Cheng C, Chin CM, Tan J et al. Prostate-specific antigen levels among Chinese, Malays and Indians in Singapore from a community-based study. Asian Pac J Cancer Prev 2007; 8: 375-8.

81 Abdallah M, Lazarev I, Ariad S, Mermershtain W. Is prostate cancer screening justified in the Bedouin population? Onkologie 2009; 32: 260-2

82 Antenor JA, Han M, Roehl KA, Nadler RB, Catalona WJ. Relationship between initia prostate specific antigen level and subsequent prostate cancer detection in a longitudinal screening study. J Urol 2004; 172: 90-3.

83 Matsubara A, Mutaguchi K, Yasumoto H, Takeshima Y, Teishima J et al. Transrecta ultrasound-guided 10-core biopsy of the prostate for Japanese patients. Hiroshima J Med Sci 2006; 55: 65-70.

84 Jeong $\mathrm{H}$, Jeong $\mathrm{BC}$, Kwak C, Lee $\mathrm{E}$, Lee SE et al. A comparison of prostate cance detection rates by 12 or 6 core biopsy at different prostate-specific antigen densities in Korean men. World J Urol 2008; 26: 395-400.

85 Park HK, Lee KY, Kim KH, Jung H, Yoon SJ et al. Intermediate versus low or high prostate-specific antigen density level: comparison of cancer detection rate between 12- and 18-core prostate biopsy. Scand J Urol Nephrol 2010; 44: 391-8.

86 Shigemura K, Arakawa S, Yamanaka K, Yasui N, Matsubara S et al. Potential predictive factors of positive prostate biopsy in the Japanese population. Int Uro Nephrol 2008; 40: 91-6.

87 Kawakami S, Numao N, Okubo Y, Koga F, Yamamoto S et al. Development, validation, and head-to-head comparison of logistic regression-based nomograms and artificial 
neural network models predicting prostate cancer on initial extended biopsy. Eur Urol 2008; 54: 601-11.

88 Roobol MJ, Steyerberg EW, Kranse R, Wolters T, van den Bergh RC et al. A risk-based strategy improves prostate-specific antigen-driven detection of prostate cancer. Eur Urol 2010; 57: 79-85.

89 Roobol MJ, Schroder FH, Kranse R. A comparison of first and repeat (four years later) prostate cancer screening in a randomized cohort of a symptomatic men aged 55-75 years using a biopsy indication of $3.0 \mathrm{ng} / \mathrm{ml}$ (results of ERSPC, Rotterdam). Prostate 2006; 66: 604-12.

90 Rochester MA, Pashayan N, Matthews F, Doble A, McLoughlin J. Development and validation of risk score for predicting positive repeat prostate biopsy in patients with a previous negative biopsy in a UK population. BMC Urol 2009; 9: 7 .

91 Kang SH, Bae JH, Park HS, Yoon DK, Moon DG et al. Prostate-specific antigen adjusted for the transition zone volume as a second screening test: a prospective study of 248 cases. Int J Urol 2006; 13: 910-4.

92 Oreste M, Giuseppe PG, Gianna P, Adriano A, Stefano N et al. Between-subject variations of transition zone epithelial volume and serum PSA levels in men with benign prostatic hyperplasia. World J Urol 2010; 28: 379-83.

93 Yadav R, Tu JJ, Jhaveri J, Leung RA, Rao S et al. Prostate volume and the incidence of extraprostatic extension: is there a relation? J Endourol 2009; 23: 383-6.

94 Patel AR, Jones JS. Optimal biopsy strategies for the diagnosis and staging of prostate cancer. Current Opinion in Urology 2009; 19: 232-37.

95 Shim HB, Park HK, Lee SE, Ku JH. Optimal site and number of biopsy cores according to prostate volume prostate cancer detection in Korea. Urology 2007; 69: 902-6.

96 Pepe P, Dibenedetto G, Gulletta M, Pietropaolo F, Minaldi G et al. Prostate cancer detection after one or more negative extended needle biopsy: results of a multicenter case-findings protocol. Arch Ital Urol Androl 2010; 82: 95-9.

97 Pepe P, Candiano G, Fraggetta F, Galia A, Grasso G et al. Is transition zone sampling at repeated saturation prostate biopsy still useful? Urol Int 2010; 85: 324-7.

98 Piros D, Fagerstrom T, Collins JW, Hahn RG. Glucose as a marker of fluid absorption in bipolar transurethral surgery. Anesth Analg 2009; 109: 1850-5.

99 Leewansangtong S, Wiangsakunna W, Taweemankongsap T. Perioperative outcomes of open radical prostatectomy versus laparoscopic radical prostatectomy in Asian men: comparison of two initial series by the same surgeon. Int Braz J Urol 2009; 35: 151-6; discussion 56-7.

100 Sundram M. Asian robotic experience. Urol Oncol 2010; 28: 677-81.

101 Yip S, Sim HG. Robotic radical prostatectomy in east Asia: development, surgical results and challenges. Curr Opin Urol 2010; 20: 80-5.

102 Vassil AD, Murphy ES, Reddy CA, Angermeier KW, Altman A et al. Five year biochemical recurrence free survival for intermediate risk prostate cancer after radical prostatectomy, external beam radiation therapy or permanent seed implantation. Urology 2010; 76: 1251-7.

103 Vu Le C, Dao OQ, Khac Tran LN. Mass screening of prostate cancer in Vietnam: current status and our opinions. Urol Oncol 2010; 28: 673-6.

104 Fukagai T, Namiki T, Carlile RG, Namiki M. Racial differences in clinical outcome after prostate cancer treatment. Methods Mol Biol 2009; 472: 455-66.

105 Fukagai T, Namiki TS, Carlile RG, Yoshida H, Namiki M. Comparison of the clinical outcome after hormonal therapy for prostate cancer between Japanese and Caucasian men. BJU Int 2006; 97: 1190-3.

106 Yoshioka Y. Current status and perspectives of brachytherapy for prostate cancer. Int J Clin Oncol 2009; 14: 31-6.

107 Yoshioka Y, Suzuki O, Kobayashi K, Teshima T, Yamada Y et al. External-beam radiotherapy for clinically localized prostate cancer in Osaka, Japan, 1995-2006: time trends, outcome, and risk stratification. Strahlenther Onkol 2009; 185: 44652.

108 Mizokami A, Ueno S, Fukagai T, Ito K, Ehara H et al. Global update on defining and treating high-risk localized prostate cancer with leuprorelin: an Asian perspective. BJU Int 2007; 99 Suppl 1: 6-9; discussion 17-8.

109 Saito T, Kitamura Y, Komatsubara S, Matsumoto Y, Sugita T et al. Outcomes of locally advanced prostate cancer: a single institution study of 209 patients in Japan. Asian J Androl 2006; 8: 555-61.

110 Chen YC, Chuang CK, Hsieh ML, Chen WC, Fan KH et al. High-dose-rate brachytherapy plus external beam radiotherapy for $\mathrm{T} 1$ to $\mathrm{T} 3$ prostate cancer: an experience in Taiwan. Urology 2007; 70: 101-5.

111 Bolla M, Fourneret P, Beneyton V, Tessier A, Jover F et al. Combination of external irradiation and androgen suppression for prostate cancer: facts and questions. Cancer Radiother 2010; 14: 510-4. French.

112 Wu RY, Wang GM, Xu L, Zhang BH, Xu YQ et al. The feasibility and safety of highintensity focused ultrasound combined with low-dose external beam radiotherapy as supplemental therapy for advanced prostate cancer following hormonal therapy. Asian J Androl 2011; 13: 499-504

113 Xylinas $E$, Dache A, Roupret M. Is radical prostatectomy a viable therapeutic option in clinically locally advanced (cT3) prostate cancer? BJU Int 2010; 106: 1596-600.

114 Clemens JQ, Markossian T, Calhoun EA. Comparison of economic impact of chronic prostatitis/chronic pelvic pain syndrome and interstitial cystitis/painful bladder syndrome. Urology 2009; 73: 743-6.

115 Calhoun EA, McNaughton Collins M, Pontari MA, O'Leary M, Leiby BE et al. The economic impact of chronic prostatitis. Arch Intern Med 2004; 164: 1231-6.

116 Basiri A, Mousavi SM, Naghavi M, Araghi IA, Namini SA. Urologic diseases in the Islamic Republic of Iran: what are the public health priorities? East Mediterr Health J 2008; 14: 1338-48.
117 Liang CZ, Li HJ, Wang ZP, Xing JP, Hu WL et al. Treatment of chronic prostatitis in Chinese men. Asian J Androl 2009; 11: 153-6.

118 Nickel JC. Recommendations for the evaluation of patients with prostatitis. World $\mathrm{J}$ Urol 2003; 21: 75-81.

119 Liang CZ, Li HJ, Wang ZP, Xing JP, Hu WL et al. The prevalence of prostatitis-like symptoms in China. J Urol 2009; 182: 558-63.

120 Krieger JN, Lee SW, Jeon J, Cheah PY, Liong ML et al. Epidemiology of prostatitis. Int J Antimicrob Agents 2008; 31 Suppl 1: S85-90.

$121 \mathrm{Hu} J \mathrm{C}$, Link CL, McNaughton-Collins M, Barry MJ, McKinlay JB. The association of abuse and symptoms suggestive of chronic prostatitis/chronic pelvic pain syndrome: results from the Boston Area Community Health survey. J Gen Intern Med 2007; 22. 1532-7.

122 Tripp DA, Nickel JC, Ross S, Mullins C, Stechyson N. Prevalence, symptom impact and predictors of chronic prostatitis-like symptoms in Canadian males aged 16-19 years. BJU Int 2009; 103: 1080-4.

123 Walz J, Perrotte P, Hutterer G, Suardi N, Jeldres C et al. Impact of chronic prostatitislike symptoms on the quality of life in a large group of men. BJU Int 2007; 100: 130711.

124 Kunishima Y, Mori M, Kitamura H, Satoh H, Tsukamoto T. Prevalence of prostatitislike symptoms in Japanese men: Population-based study in a town in Hokkaido. Int J Urol 2006; 13: 1286-9.

125 Lee SW, Cheah PY, Liong ML, Yuen KH, Schaeffer AJ et al. Demographic and clinical characteristics of chronic prostatitis: prospective comparison of the University of Sciences Malaysia Cohort with the United States National Institutes of Health Cohort. J Urol 2007; 177: 153-7; discussion 58.

126 Zhou YH, Mei RB, Zhao ST, Zhang J. Sexual function and sexual life quality of chronic prostatitis patients: a clinical investigation. Zhonghua Nan Ke Xue 2010; 16: 33640. Chinese.

127 Liang CZ, Hao ZY, Li HJ, Wang ZP, Xing JP et al. Prevalence of premature ejaculation and its correlation with chronic prostatitis in Chinese men. Urology2010; 76: 962-6.

128 Magri V, Perletti G, Montanari E, Marras E, Chiaffarino F et al. Chronic prostatitis and erectile dysfunction: results from a cross-sectional study. Arch Ital Urol Androl 2008; 80: $172-5$.

129 Lee SW, Liong ML, Yuen KH, Leong WS, Cheah PY et al. Adverse impact of sexual dysfunction in chronic prostatitis/chronic pelvic pain syndrome. Urology 2008; 71: 79-84.

130 Schultheiss D. Urogenital infections and male sexuality: effects on ejaculation and erection. Andrologia 2008; 40: 125-9.

131 Sonmez NC, Kiremit MC, Guney S, Arisan S, Akca O et al. Sexual dysfunction in type III chronic prostatitis (CP) and chronic pelvic pain syndrome (CPPS) observed in Turkish patients. Int Urol Nephrol 2010; 43: 309-14

132 Kiyota H, Onodera S, Ohishi Y, Tsukamoto T, Matsumoto T. Questionnaire survey of Japanese urologists concerning the diagnosis and treatment of chronic prostatitis and chronic pelvic pain syndrome. Int J Urol 2003; 10: 636-42.

$133 \mathrm{Ku} \mathrm{JH}$, Paick JS, Kim SW. Factors influencing practices for chronic prostatitis: a nationwide survey of urologists in South Korea. Int J Urol 2005; 12: 976-83.

134 Murphy AB, Nadler RB. Pharmacotherapy strategies in chronic prostatitis/chronic pelvic pain syndrome management. Expert Opin Pharmacother2010; 11: 1255-61.

135 El-Nashaar A, Shamloul R. Antibiotic treatment can delay ejaculation in patients with premature ejaculation and chronic bacterial prostatitis. J Sex Med 2007; 4: 491-6.

136 Zohdy W. Clinical parameters that predict successful outcome in men with premature ejaculation and inflammatory prostatitis. J Sex Med 2009; 6: 3139-46.

137 Tugcu V, Tasci Al, Fazlioglu A, Gurbuz G, Ozbek E et al. A placebo-controlled comparison of the efficiency of triple- and monotherapy in category III B chronic pelvic pain syndrome (CPPS). Eur Urol 2007; 51: 1113-7; discussion 18.

138 Wagenlehner FM, Schneider H, Ludwig M, Schnitker J, Brahler E et al. A pollen extract (Cernilton) in patients with inflammatory chronic prostatitis-chronic pelvic pain syndrome: a multicentre, randomised, prospective, double-blind, placebocontrolled phase 3 study. Eur Urol 2009; 56: 544-51.

139 Murphy AB, Macejko A, Taylor A, Nadler RB. Chronic prostatitis: management strategies. Drugs 2009; 69: 71-84.

140 Yan S, Li HZ, Zhang XY, Li HJ. Retrospective analysis of the combined therapy of terazosin with chlormezanone for chronic prostatitis/chronic pelvic pain syndrome. Zhonghua Nan Ke Xue 2009; 15: 717-20. Chinese.

141 Marszalek M, Wehrberger C, Temml C, Ponholzer A, Berger I et al. Chronic pelvic pain and lower urinary tract symptoms in both sexes: analysis of 2749 participants of an urban health screening project. Eur Urol 2009; 55: 499-507.

142 Zaak D. Editorial comment on: Chronic pelvic pain and lower urinary tract symptoms in both sexes: analysis of 2749 participants of an urban health screening project. Eur Urol 2009; 55: 507

143 Laudico AV, Mirasol-Lumague MR, Mapua CA, Uy GB, Toral JA et al. Cancer incidence and survival in Metro Manila and Rizal province, Philippines. Jpn J Clin Oncol 2010; 40: 603-12.

144 Chia SE, Tan CS, Lim GH, Sim X, Lau W et al. Incidence, mortality and five-year relative survival ratio of prostate cancer among Chinese residents in Singapore from 1968 to 2002 by metastatic staging. Ann Acad Med Singapore 2010; 39: 466-71.

145 Bouchardy C, Fioretta G, Rapiti E, Verkooijen HM, Rapin CH et al. Recent trends in prostate cancer mortality show a continuous decrease in several countries. Int $J$ Cancer 2008; 123: 421-9. 